\title{
SISTEM VEZNIKA U ORHONSKIM NATPISIMA
}

Orhonski natpisi predstavljaju najstarije književne pisane spomenike turskog jezika. Potiču iz 8.veka i pružaju precizne podatke o nastanku najstarije turske države. Jezik orhonskih natpisa je jedan od dijalekata kojim su govorili Gokturci, preci današnjih Turaka. Danas se taj dijalekat zvanično naziva staroturskim jezikom. On je prilično udaljen od svog savremenog naslednika i u sebi sadrži sistem veznika od kojih većina nije više u upotrebi. Savremeni turski gramatičari smatraju da veznici nisu svojstveni turskom jeziku. Veznici koji su prisutni u tekstovima sa orhonskih spomenika su po svome poreklu gerundiji ili postpozicije koji vrše vezničku funkciju u rečenici, a u ređim slučajevima se u navedenoj funkciji javlja čak i kopulativni glagol. Aglutinativni jezik kao što je turski, u velikoj meri neguje asindetske rečenice koje su zastupljenije što se više ide u prošlost. Tokom svog razvoja i pod uticajem drugih jezika, stari turski jezik je počeo da koristi određene vrste reči kao što su to gerundiji ili postpozicije koje su kasnije u potpunosti preuzele funkciju koordinativnih i subordinativnih veznika $\mathrm{U}$ ovom radu će biti reči o poreklu veznika koji se mogu pratiti do najranijih pisanih spomenika na turskom jeziku i njihovim ekvivalentima u savremenom turskom jeziku sa ciljem ukazivanja na evoluciju sistema veznika.

Ključne reči: orhonski natpisi, Gokturci, staroturski jezik, gerundiji, postpozicije, sistem veznika, aglutinativni jezik, asindetska rečenica, koordinativni veznici, subordinativni veznici

\section{Istorijat orhonskih natpisa}

Orhonski natpisi su prvi registrovani pisani spomenici Turaka iz 8 . veka koji nam daju precizne podatke o istoriji i civilizaciji najstarije turske države. Jezik ovih natpisa je stari dijalekt turskog jezika dešifrovan još u 19. veku. Njime su govorili drevni Turci - Gokturci (Göktürkler), koje su 
Kinezi zvali Tü-Küe i koji su prvobitno živeli između reke Orhona i donjeg sliva reke Jenisej u Mongoliji. Dijalekat kojim su pisani Orhonski natpisi je bio zvanični jezik drugog Istočnog turskog carstva u periodu 680-740. n.e. (Tekin, 2012: 22). U naučnoj orijentalistici je za ovaj dijalekat u upotrebi bilo više naziva. Radlov (Radloff) ga je zvao staroturski (Alttürkisch), dok je V. Bang (Wilhelm Bang) koristio naziv kokturski (kökturkisch). Kod N. A. Baskakova (Никола́й Алекса́ндрович Баска́ков) је prisutan termin starooguski ili staroujgurski (Kononov, 1956: 195)

Orhonski natpisi su pronađeni na teritoriji današnje Mongolije, u dolini reke Orhon, po kojoj i nose ime. Natpisi potiču od starih turskih vladara Gultekina (Kül Tigin), Bilge Kagana (Bilge Kagan), Tonjukuka (Tonyukuk), Išbara Tarkana (İşbara Tarkan). Ruski arheolog N. M. Jadrincev (Никола́й Миха́йлович Ядри́нцев) је 1889. godine otkrio pomenute natpise, ali je čast da ih dešifruje pripala Dancu Vilhelmu Tomsenu (Vilhelm Ludwig Peter Thomsen) četiri godine kasnije. Pronađeni spomenici govore o mitskom poreklu Turaka, o zlatnom dobu njihove istorije, padu pod kinesku vladavinu i konačno, oslobođenju pod vođstvom Bilge Kagana.

Iako su veoma važni sa stanovišta političke istorije Turaka, Orhonski natpisi, kao najstariji pisani spomenik na turskom jeziku pokazuju, kada je reč o veznicima, u kojoj je meri došlo do promena u broju i učestalosti upotrebe veznika. Prilikom obrade ove teme neophodno je naglasiti da je veliki doprinos razumevanju jezika Orhonskih natpisa dao Ahmet Bidžan Erdžilasun (Ahmet Bican Ercilasun) baveći se isključivo književnim aspektom natpisa na spomenicima vladara Tonjukuka i Gultekina. U ovom radu će pažnja biti usmerena na pomalo kontroverznu temu veznika u turskom jeziku ${ }^{1}$, odnosno ukazivanje na poreklo veznika u Orhonskim natpisima i njihove ekvivalente u savremenom turskom jeziku.

\section{Veznici u Orhonskim natpisima}

Prema definiciji, veznici su reči ili izrazi koji vezuju delove jedne rečenice ili čitave rečenice (Đinđić, 1991:330). U skladu sa ustrojstvom turske rečenice, veznici su najčešće prisutni u kraćim rečenicama (Hengirmen, 1995:175). Broj reči koje imaju funkciju veznika se u bitno razlikuje između starog turskog i savremenog turskog jezika. Pravih veznika u savremenom turskom jeziku je malo (Gencan, 1979:446). Većina veznika iz

1 Mnogi turski gramatičari smatraju da ne postoje izvorno turski veznici (prim.aut.). 
starog jezika nije u upotrebi u savremenom jeziku. Glavni razlog za ovakvu drastičnu promenu leži u činjenici da je turski jezik u srednjem veku pretrpeo veliki uticaj arapskog i persijskog jezika (Demir\&Y1lmaz, 2009:142) od kojih je preuzeo mnoge veznike, što je za posledicu imalo i promenu na sintaksičkom planu rečenice koja je je sve više imala sindetsko ustrojstvo.

U tekstovima Orhonskih natpisa prisutne su dve grupe veznika: koordinativni i subordinativni (Tekin, 1997: 168). Takođe valja napomenuti da su üçün i artuq jedini veznici koji po svom poreklu nisu gerundiji.

Posmatrajući turski jezik iz dijahronijske perspektive, ovde će se pokazati kako je zapravo došlo do formiranja veznika od reči sa glagolskim značenjem.

Transkripcija i prevod na savremeni turski jezik rečenica sa veznicima preuzeti su iz navedenog dela T.Tekina, dok je prevod na srpski jezik autorski.

\subsection{Koordinativni veznici}

Prema definiciji, ovi veznici (konjunktori) služe za povezivanje (koordinaciju) dve ili više nezavisnih rečenica u jednu nezavisnosloženu rečenicu.

Azu 'ili' (od korena az "zastraniti“) (Академия Наук CCCP, 1963:43).

Po poreklu ovaj veznik predstavlja gerundij (Tekin, 1997: 168). Prvi put se pojavljuje na Orhonskim natpisima koji se pripisuju Guntekinu, i to na njihovoj južnoj strani.

Ovaj veznik je preveden zahvaljujući korelaciji sa tuvinskim korenom azi u značenju 'zastraniti'. Takođe, ovaj veznik je prisutan u kazaškom jeziku u formi $a z$ ili u jakutskom u formi $a s$.

Ekvivalent pomenutog veznika u savremenom turskom jeziku je rastavni veznik veya (ili) ili suprotni veznik fakat (samo, nego) koji su doslovno preuzeti iz arapskog jezika.

Azu bu sabïmda igid bar $\gamma u$ ? (Tekin, 1997: 168).

Yoksa, bu sözümde yalan var mi?

Ili možda ima laži u mojim rečima?

Artuqi ' još', 'i više', (od korena artuq 'višak' sa dodatkom prisvojnog sufiksa trećeg lica jednine -i ) (Академия Наук CCCP, 1963:57). 
Ovaj veznik je prvi put zabeležen na jugozapadnoj strani spomenika podignutog od strane Bilge Kagana (Tekin, 1997: 168). Za pomenuti veznik se tvrdi da je jedini veznik koji po svome poreklu nije gerundij (Tekin, 1997: 168). Ovaj veznik je prisutan i u savremenom turskom jeziku, i to u svom nesufigiranom obliku u artık ( još, konačno, više). Neophodno je spomenuti da u savremenom truskom jeziku postoji i glagol artmak, u značenju "povećati se, biti višak". Ovaj veznik koji se pojavljuje u najstarijim pisanim spomenicima, ima svoj ekvivalemt u savremenom turskom jeziku kao sastavni veznik ve (i).

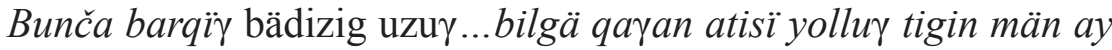
artuqï tört kün olurup bitidïm bädiztim (Tekin, 1997: 168).

Bilge Kă̆an kitabesini Yollug Tigin, yazdım. Bunca türbeyi, resimi, sanatı ... kağanın yeğeni $i$ ollug Tigin ben bir ay (artı) dört gün oturup yazdim.

Sve ove statue, slike i ukrase... Ja, princ Joluk, sestrić Bilge Kagana,

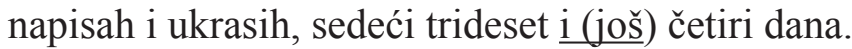

Biriki 'i' (od korena birik 'pridružiti, spojiti') (Академия Наук CCCP, 1963:102).

Prvi put je ovaj veznik zabeležen na južnoj strani spomenika posvećenoj vladaru Guntekinu. Važno je napomenuti da se ovaj veznik (Tekin 1997:170) smatra gerundijem glagola birikmek 'sakupiti, okupiti', s obzirom da su se gerundiji u starom turskom jeziku formirali dodavanjem nastvka - $i$ na infinitivnu osnovu. U savremenom turskom jeziku postoji dosta sličan oblik beriki u značenju 'najbliži, ovaj, pomenuti'. Prema Tekinu, ovaj veznik se na savremeni turski jezik prevodi sastavnim veznikom ve 'i'.

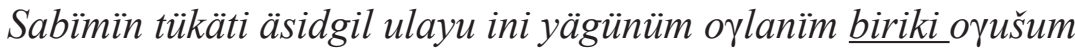
bodunum. Sözümü tamamiyle işit. Bilhassa küçük kardeş,yeğenim. (Tekin, 1997: 169).

Poslušajte me od početka do kraja, svi vi, moja mlađa braćo $\underline{\text { i moja }}$ deco i moja rodbino...

Taqï 'i' u složenici anča-taqï 'više nego' (Академия Наук CCCP, 1963:536). 
Po prvi put je pomenuti veznik zabeležen na južnoj strani spomenika posvećenog vladaru Guntekinu. Po svome obliku predstavlja prilog za način (Tekin, 1997: 150), izveden od glagola takmak ( spojiti, dodati, zakačiti za) koji je prisutan i u savremenom turskom jeziku u istom značenju. Ekvivalent ovog veznika u savremenom turskom jeziku je sastavni veznik ve (i).

$B[u \ldots i l]$ erser, anca takı erig yirte irser, anca erig yirte berfggü taş tokıtdım, bitid [d]im.

Il ise, şöyle daha erişilir yerde ise, işte öyle erişilir yerde ebedî taş yontturdum, yazdırdım. (Tekin, 1997: 169).

Otkada je ovo glavno (?) mesto i mir vlada na velikoj teritoriji, na ovakvom mestu ja ispisah i podigoh kamen za uspomenu.

$\boldsymbol{U} \boldsymbol{d u}$ 'i' (dosl. 'koji sledi') od ud 'slediti' (Академия Наук CCCP, 1963:605)

Po prvi put je ovaj veznik zabeležen na istočnoj strani Orhonskih natpisa posvećenih vladaru Tonjukuku (Tekin, 1997: 169). Zapravo se radi o glagolu imek 'biti' koji je prisutan u savremenom turskom jeziku kao kopulativni glagol u imenskoj rečenici. U starom tuskom jeziku je imao funkciju pravog glagola sa značenjem 'slediti'. Ekvivalent ovog veznika u savremenom turskom jeziku je sastavni veznik ve (i).

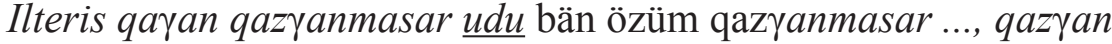
tuqīn üčün $\underline{u d u}$

özüm qazүantuqum üčün il yämä il boltï bodun yämä bodun boltï.

Ilteriș Kağan kazanmasa udu, ben öz'üm kazanmasam...Kazandığg [için] udu öz'üm kazandığım için il yine il oldu, boy yine boy oldu. (Tekin, 1997: 169).

Da Ilteriš Kagan nije pobedio, i da ja nisam pobedio, ..., pošto je on pobedio, i pošto sam ja pobedio, obe države su postale države $i$ narod je postao narod.

Ulayu 'i' (dosl. 'koji povezuje') od ula- 'povezati, pridružiti, spojiti’ (Академия Наук СССР, 1963:615)

Pomenuti veznik je prvi put zabeležen na istočnoj strani spomenika posvećenog vladaru Guntekinu. Ovaj veznik je upotrebljen u funkciji 
sastavnog veznika ' $i$ '. Po svom obliku on predstavlja gerundij $-a /-e$ od glagola ulamak (Tekin, 1997: 168). Pomenuti glagol je prisutan i u savremenom turskom jeziku u značenju 'dodati, pridružiti'. Pored toga što ima funkciju sastavnog veznika, ovaj gerundij u vezničkoj funkciji se može smatrati za interpunkcijski znak zareza, upotrebljen za nabrajanje.

Ögum qatun ulayu öglärim äkälärim käliqünüm qunčuylärïm, ... ,

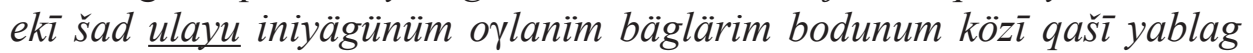
boltači tip saqüntïm

Annem hatun ve analarım, ablalarım, gelinlerim, prenseslerim,... Íki şadın ve küçük kardeş yeğenimin, oğlumun, beylerimin, milletimin gözü kaşı kötü olacak diyip düşünceye daldım. (Tekin, 1997: 168).

Moja majka, žena i moje maćehe, starije sestre, snaje, moje princeze..., "plašim se da su oči trepavice moje mlađe braće, sinova, velmoža $i$ naroda propali od plakanja."

Yämä 'i, takođe' od korena yäm 'dodati' (Академия Наук CССР, 1963:231)

Pomenuti veznik je prvi put zabeležen na istočnoj strani Orhonskih natpisa posvećenih vladaru Guntekinu (Tekin, 1997: 170). Sličan oblik je zabeležen i u mongolskom jeziku kao 'neme'. Prema svojoj konstrukciji predstavlja gerundij $-a /-e$ od glagola koji više nije u upotrebi. Ekvivalent ovog veznika u savremenom turskom jeziku je sastavni veznik ve ' $\mathrm{i}$ '.

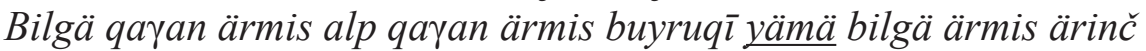
alp ärmis ärinč.

Bilgili kağan imiş, cesur kağan imiş. Buyruku yine bügili imiş tabî̂, cesur imiş tabiî. (Tekin, 1997: 170)

Mudri kagani su bili pametni i hrabri.

Postoje slučajevi kada se ovaj veznik pojavljuje reduplicirano yämä,..., yämä u značenju 'i ... i' što dosta podseća na konstrukciju ,hem ... hem de“ u savremenom turskom jeziku. Ovakav način upotrebe veznika je zabeležen na istočnoj strani spomenika posvećenog vladaru Tonjukuku.

Bäglarī yämä bodunī yämä tüz ärmis.

Beğleri yine boylarl yine düz imiş. (Tekin, 1997: 170)

I vladari i narodi su bili mirni. 
Veznik yämä može biti čak ponovljen i tri puta (Tekin, 1997: 171)

Ovakav način upotrebe ovog veznika ukazuje da je reč o vezniku za nabrajanje.

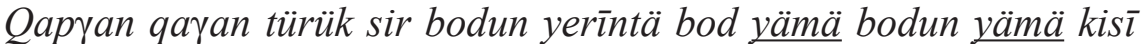
yämä idi yoq ärtäči ärti.

Kapağan Kağanıın Türk Sir boylarının yerinde boy vine, boylar yine, kişi yine iyi [ce] yok edecek idi. (Tekin, 1997: 171)

Pod Kapkagan Kaganom ne bi bilo ni plemena ni ljudi ni ničega.

\section{Subordinativni veznici}

Ovi veznici služe za iskazivanje odnosa zavisnosti jedne ili više rečenica u odnosu na glavnu rečenicu (Čaušević, 1996:491)

U literaturi je zabeleženo šest zavisnih veznika i svi su po svome poreklu gerundiji, izuzev veznika artuqi (Ergin, 1997: 95).

U najstarijem turskom tekstu postoje i subordinativni veznici, iako je turski jezik iz toga perioda veoma sklon asindetskim konstrukcijama. Pomenuti veznici su veoma frekventni u tekstovima Orhonskih spomenika. Međutim, samo jedan od njih se sačuvao u savremenom turskom jeziku, i to u fonetski izmenjenom obliku. Radi se o vezniku üçün (için).

3.1. Üçün ‘jer, kao, zbog’ (Академия Наук ССCР, 1963:622)

Navedeni veznik po svome obliku podseća na tursku postpoziciju için ('za, zbog').Upotrebljava se za uvođenje uzročnih rečenica. Prvi put je zabeležen na istočnoj strani spomenika posvećenog vladaru Guntekinu (Ercilasun 2004: 132). Predstavlja zavisni veznik čija fonetska varijanta için postoji i u savremenom turskom jeziku. U periodu Karahanidskog turskog jezika u 11. veku zabeležene su moge fonetske promene u odnosu na stari turski jezik. Tako je došlo i do promene okruglog vokala ü u široki vokal $i$ (Demir\&Y1lmaz, 2009:71). Gore pomenuti veznik se najčešće pojavljuje posle predikativnih konstrukcija zavisne rečenice i povezuje ih sa nezavisnom rečnicom. Samim time, nosi značenje namernog veznika ' da bi' i predloga 'za'.

Qutum bar üčün ülügüm bar üčün öltäči bodunuү tirgürü igit(t)im.

Devletim, klsmetim var olduğu için, ölecek milleti diriltip besledim. (Tekin, 1997: 171)

Pošto sam imao sreću, dao sam život ugroženima i podigao sam ih. 
Teyin, tiyin 'jer, zato što, zbog' (dosl. 'govoreći') (Академия Наук CCCP, 1963:549)

Prvi put je ovaj veznik primećen na istočnoj strani Orhonskih spomenika posvećenih Bilge Kaganu (Tekin, 1997: 171). Po svome obliku ovaj veznik predstavlja gerundij koji predstavlja fonetsku varijantu gerundija glagola demek ('kazati'). Funkcija ovog veznika je da poveže uzročnu rečenicu sa glavnom. Ekvivalent ovog veznika u savremenom turskom jeziku je gerundij diye koji se upotrebljava kao namerni veznik, ali i kao znak za direktni govor.

Arqǐs ïdmaz tiyin sülädim.

Kervan etmez diye sevk ettim. (Tekin, 1997: 171)

Otišao sam u pohod pošto nisu poslali karavane.

Tip 'da bi, sa namerom da' (dosl. 'govoreći)) (Академия Наук CCCP, 1963:561)

Kao i prethodni veznik, otkriven je na istočnoj strani spomenika posvećenih Bilge Kaganu. Po svome obliku predstavlja gerundij na -ip od glagola demek ('kazati'). Poseduje isto značenje kao savremeni veznik diye. Na srpski jezik se prevodi namernim veznikom 'da bi'. Ovaj subjunktor ima veoma široku upotrebu u savremenom turskom jeziku. Njegova široka upotreba dolazi od njegovog osnovnog značenja, a to je da markira direktni govor, odnosno glagolski prilog sadašnji "govoreći”. Iz ovakve uporebe gerundija koja je uslovljena sklonošću starog turskog jezika ka asindetskim rečenicama, vremenom su diferencirana mnoga značenja subordinacije (Čaušević, 1996:510).

Anї anïtayīn tịp sülädim.

Onu korkutayım deyip sevk ettim. (Tekin, 1997: 172)

Da bih ih zaplašio krenuo sam u pohod na njih.

\section{Gerundiji u funkciji veznika}

Iako gerundiji u srpskom jeziku ne mogu da se percipiraju kao pravi veznici, u turskom jeziku oni imaju funkciju veznika, to jest, poseduju osobine subordinacije i koordinacije. Zato ih je neophodno navesti s obzi- 
rom da postoji značajan broj gerundija koji vrše funkciju veznika. Asindetske rečenice su bile svojstvene starom turskom jeziku. One su se formirale tako da se jednostavne rečenice nižu jedna do druge tako da među njima postoji neka uska smisaona veza. Dakle, odnos na semantičkom planu može biti i zavisan i nezavisan (Čaušević, 1996:479). Gerundiji su tako bili prirodna granica između dve rečenice. Oni imaju finalnu poziciju u rečenici, budući da je takav položaj glagola i glagolskih reči jedna od karakteristika aglutinativnih jezika. Iz njihovog položaja proizilazi i veznička funkcija gerundija.

\subsection{Gerundij na $-p$ ' $i$ '}

Ovaj gerundij upućuje na radnju koja se desila pre neke druge radnje. Po svome obliku je dosta sličan gerundiju -ip koji se koristi u savremenom turskom jeziku. Način upotrebe ovog gerundija je ostao nepromenjen sve do danas. Prvi put je zabeležen na severnoj strani spomenika posvećenog Bilge Kaganu (Tekin, 1997: 182). Ovaj gerundij upućuje na radnje koje su se sukcesivno dešavale. Kao i sve gerundije karakteriše ga odsustvo lica. To znači da se koristi u funkciji nabrajanja radnji koje je izvršilo isto lice. S obzirom da ima funkciju nabrajanja, to nas dovodi do zaključka da ga je moguće upotrebiti i kao znak zareza, a ne samo sastavnog veznika ve (i).

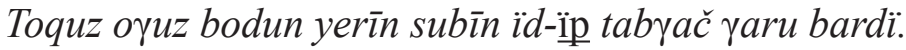

Dokuz Oğuz boylarl, yerini, suyunu bırakıp Çin'e vard1. (Tekin, 1997: 182)

Narodi Tokuz-Oguz napustiše svoju zemlju í odoše put Kine.

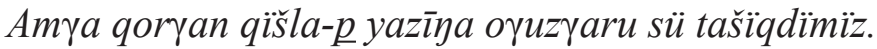

Amga Kurgan>da kışlayıp yazın[d]a Ŏguz>a doğrusü taşındık. (Tekin, 1997: 182)

Proveli smo zimu u Amga-Korganu ína proleće krenusmo na Oguze.

\subsection{Gerundij na-pan /-pän ' $i$ '}

Pomenuti gerundij predstavlja proširenu verziju gore pomenutog gerundija na -ip. Zabeležen je kako na istočnoj strani spomenika Bilge Kaganu tako i istočnoj strani spomenika Tonjukuku (Tekin, 1997: 183). S 
obzirom da predstavlja prošireni oblik gerundija -ip, ukazuje na sukcesivne radnje. Na srpski jezik se najčešće može prevesti sastavnim veznikom ve (i). U savremenom turskom jeziku najčešće je zamenjen gerundijom -ip, veznikom ve ili jednostavno znakom zareza.

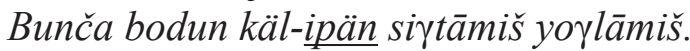

Bunca boyları gelip ağlamış, yas tutmuş. (Tekin, 1997: 183)

Mnogi ljudi dođoše i behu u žalosti.

Sülä_pan tört bulundaqï bodunu q qop alamis qop baz qülmis.

Ordu sevk ederek dört taraftaki milleti hep almış, hep tâbi k1lmış. (Tekin, 1997: 183)

Krenuli su sa vojskama, pokorili su i zavladali narodima sa sve četiri strane sveta.

\subsection{Gerundij -ÿ̈n/-yin 'nakon što>}

Po prvi put je zabeležen na istočnoj strani spomenika posvećenog Tonjukuku (Tekin, 1997: 183). Njegova upotreba i značenje su isti kao kod već pomenutog gerundija $-a /-e$. Slični oblici postoje u kipčačkom jeziku $(-y)$, odnosno u čagatajskom -may/- mey. Ovaj gerundij se retko javlja u tekstovima na starom turskom jeziku. Po funkciji je isti kao i gerundij naince koji u savremenom turskom jeziku ima vremensko značenje i prevodi se temporalnim subjunktorom 'kada'. Na isti način se prevodi i na srpski jezik, s obzirom da je reč o radnji koja je završena i koja prethodi nekoj drugoj radnji.

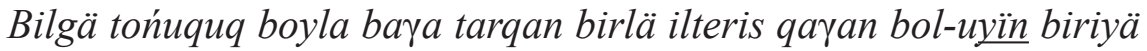

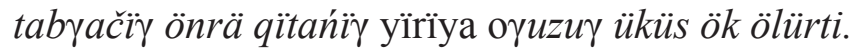

Tonyukuk, Boyla Băga Tarkan ile İlteriş kağan olunca beride Tabgaçı önde Kıtayı, yukarıda Oğuz'u pek çok öldürdü. (Tekin, 1997: 183)

I kada je postao kagan u društvu Bilge Tonjukuk Bojla Baga Tarkana, Ilteriš je pobio mnoge Kineze na jugu, Kitajce na istoku i Oguze na severu.

\subsection{Gerundij teyin tiyin 'govoreći'}

Koristi se kao marker za direktni govor. Po svojoj upotrebi odgovara gerundiju

-diye koji je zastupljen u savremenom turskom jeziku. Zabeležen je na istočnoj strani spomenika Tonjukuku. Po svome obliku predstavlja 
prošireni oblik prethodnog gerundija. Na srpski jezik se može prevesti glagolskim prilog 'govoreći' ili jednostavno interpunkcijski, znacima navoda. Kögmän yolì bir ärmis tumis te-yin äsidip.

Kögmen'in yolu bir imiş, tu[tuk]muş diye işitip(Tekin, 1997: 184)

Tada sam čuo da ima samo jedan put za Kogmen, i on je pod snegom.

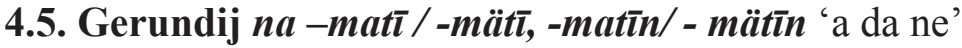

Ovaj gerundij služi kao negacija gerundija na $-a /-\ddot{a},-\ddot{i} /-i,-u /-\ddot{u}$, $i-p$, - pan/ -pän. Po svome značenju i funkciji sličan je gerundiju -madan koji je zastupljen u savremenom turskom jeziku. On služi za građene načinskih priloga od glagola. Poseduje značenje suprotnog veznika $a$ ili priloga za način u srpskom jeziku.

Tün udi-matī küntüz olur - matī... isig küčüg bertim ök.

Gece uyuyamadım, gündüz oturmadan, kızll kanımı döktü, kara terimi yögürrdü, işi gücü [ona] verdim ök. (Tekin, 1997: 184)

Služio sam (kaganu), a da nisam spavao noću i odmarao se danju.

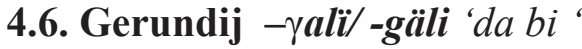

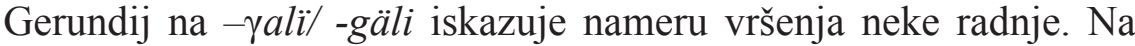
srpski jezik se prevodi konstrukcijom ' $d a b i$ '. U savremenom turskom jeziku više nije u upotrebi, već se umesto njega koristi skraćeni infinitiv u dativu koji pokazuje nameru vršenja radnje.

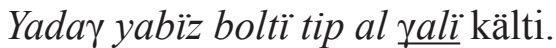

Yaya, yavuz oldu deyip almaya geldi. (Tekin, 1997: 184)

Došli su da nas pokore misleći da nemamo konje i da smo u lošem stanju.

Isti gerundij ukazuje i na radnju koja se dešava paralelno sa radnjom glavne rečenice. tada nosi značenje gerundija -eli koji se u savremenom turskom jeziku koristi za uvođenje vremenske rečenice.

\subsection{Gerundij ärkli ,koji jeste}

Ova supstantivirana forma participa ärkli «koji jeste', zajedno sa participom na $-r$ gradi gerundij i označava radnju koja počinje da se dešava u trenutku dok traje radnja glavne rečenice. Prvi put je otkriven na istočnoj strani spomenika posvećenog vladaru Tonjukuku (Tekin, 1997: 186). U 
savremenom turskom jeziku njegov ekvivalent je gerundij -ken. Na srpski jezik prevodi se veznikom za vremensku rečenic , dok'.

Kül Tigin yiti otuz yaşıriga Karluk budun erür barur erkli yağı boldl.

Kül Tigin yirmi yedi yaşına gelince Karluk kavmi hür ve müstakil iken düşman oldu. (Tekin, 1997: 186)

Kada je Guntekin napunio dvadeset i sedam, Karluci koji su slobodni, postadoše dušmani.

\section{Zaključak}

Nakon deskriptivne analize karakteristika i funkcija veznika i vezničkih priloga koji se pojavljuju u Orhonskim natpisima i njihovog upoređivanja sa savremenim turskim jezikom, može se zaključiti da je ova vrsta reči, bez obzira na to što pojedini gramatičari negiraju njeno postojanje ili je smatraju nesvojstvenom turskom jeziku, veoma je zastupljena i igra veoma važnu ulogu u iskazivanju različitih odnosa između rečenica i rečeničnih delova. U najstarijem pisanom spomeniku na turskom jeziku nalazi se relativno mali broj pravih veznika. Njihovu funkciju vrši veliki broj gerundija ili relativno mali broj imenica koje su poprimile osobine veznika. Odnosi subordinacije i koordinacije u staroturskom jeziku su mnogo češće bili iskazivani promenom položaja rečeničnih delova nego upotrebom veznika. Do današnjeg dana se održao mali broj veznika koji su zabeleženi u staroturskom jeziku, ali su se zato pojavili mnogi ,pravi“ veznici. Osim toga, gerundiji, kao glagolske reči i dalje vrše svoju ulogu vezničkih elemenata, s obzirom da je položaj glagolskih reči u turskoj rečenici ostao nepromenjen do danas. Ovo istraživanje je utoliko značajno što pokazuje iz dijahronijske perspektive, veliku razliku u broju veznika, odnosno vezničkih konstrukcija. Razvitkom jezika, nauke i kulture kao i kontaktima sa drugim jezicima došlo je do prodora mnogih reči (veznika) koji su neminovno uticali na sintaksičko ustrojstvo u okviru turske rečenice.

\section{LITERATURA}

Академия Наук СССР. (1969). Древнетюрский Словарь. Ленинград: Издательство Наука.

Čaušević, E. (1996). Gramatika suvremenoga turskog jezika. Zagreb: Hrvatska sveučilišna naklada. 
Demir,N.,Yılmaz.E. (2009). Türk Dili. Ankara: Ofset Yayıncılık.

Ercilasun, A.B. (2004). Türk Dili Tarihi. Ankara: Akçăg.

Đinđić, S. (1991). Udžbenik turskog jezika.Beograd: Naučna knjiga.

Gencan,T.N. (1979). Dilbilgisi. Ankara: Türk Dil Kurumu Yayınları.

Hengirmen, M. (1995). Türkçe Dilbilgisi. Ankara: Engin Yayınevi.

Lewis, G. L. (1985). Turkish Grammar. Oxford: Oxford at the Clarendon Press.

Кононов, А. Н.(1956). Грамматика современного турецкого литературного языка. Москва: Академии наук СССР.

Tekin, T. (1997). A Grammar of Orkhon Turkic.London: Routledge.

\section{Saša Bradašević}

SYSTEM OF CONJUCTIONS IN THE ORKHON INSCRIPTIONS

\section{Summary}

The Orkhon inscriptions represent the oldest written records of Turkish language. They date back to 8th century A.D. and they offer precise information about establishing the oldest Turkic state. The language of The Orkhon Inscriptions is actually one of the dialects spoken by the Gokturks, the ancestors of the modern Turks. Today, that dialect is officially called the Old Turkish. It is quite distant from its modern day heir, and contains within itself the system of conjuctions that are not in use in modern language. Many Turkish grammerians advocate the idea that conjuctins are not innate to Turkish language. The conjuctions present in the Orkhon Inscriptions are gerunds or postpositions by its origin, having the role of the conjuction in a phrase or a sentence. There are cases, however, when the copulative verb was used in the same manner. As a member of agglutinative languages, Turkish language gives yield to asyndetic constructions especially when one goes further back in history of language. With the evolution of language and after many influences from other cultures and languages, hte Old Turkish begun to introduce certain word groups such as gerunds and postpositions, that overtook the function of both subordinate and coordinate conjuctions.

Key words: Orkhon Inscriptions, Gokturks, Old Turkish, gerunds, postpositions, system of conjuctions, agglutinative language, asyndetic sentence, subordinate conjuctions, coordinate conjuctions. 